\title{
Obesity, albuminuria and hypertension among Hong Kong Chinese with non-insulin-dependent diabetes mellitus (NIDDM)
}

\author{
J.C.N. Chan, C.K. Cheung ${ }^{1}$, R. Swaminathan ${ }^{1 *}$, M.G. Nicholls ${ }^{2 \dagger}$ and \\ C.S. Cockram ${ }^{2}$
}

Departments of Clinical Pharmacology, ${ }^{1}$ Chemical Pathology and ${ }^{2}$ Medicine, Chinese University of Hong Kong, Prince of Wales Hospital, Shatin, N.T., Hong Kong

Summary: A total of 412 Hong Kong Chinese diabetic patients were studied on at least two occasions 8-16 weeks apart. Although $28 \%$ were insulin-treated, only $3.6 \%$ had insulin-dependent diabetes (IDDM). In the remaining 397 patients with non-insulin-dependent diabetes (NIDDM), the mean (s.d.) body mass index (BMI) was $24.4 \pm 3.2 \mathrm{~kg} / \mathrm{m}^{2}$ in females and $24.2 \pm 3.2 \mathrm{~kg} / \mathrm{m}^{2}$ in males. Obesity was present in $17 \%$ of males $\left(B M I>27 \mathrm{~kg} / \mathrm{m}^{2}\right)$ and $40 \%$ of females $\left(B M I>25 \mathrm{~kg} / \mathrm{m}^{2}\right)$. Established hypertension was present in $49 \%$. Abnormal albuminuria, defined as a mean urinary albumin/creatinine (UA/Cr) ratio greater than $5.4 \mathrm{mg} / \mathrm{mmol}$ based on two random spot urine samples, was present in $47 \%$. On stepwise multiple regression analysis, $\mathrm{UA} / \mathrm{Cr}$ ratio $\left(R^{2}=0.34, F=65.4, P<0.001\right)$ showed significant associations with systolic blood pressure (standardized regression coefficient $\beta=0.40$, $P<0.001)$, plasma creatinine concentration $(\beta=0.27, P<0.001)$ and glycosylated haemoglobin $(\beta=0.20, P<0.001)$. While the prevalence of hypertension increased with increasing severity of proteinuria, $\mathbf{4 0} \%$ of normoalbuminuric patients had hypertension. Among patients diagnosed before the age of $35(n=67), 52 \%$ were insulin-treated although only $10 \%$ were insulin-dependent. Among these NIDDM patients of young onset $(n=59)$, obesity was present in $25 \%$ of males and $56 \%$ of females. Overall, $18 \%$ of these patients had a blood pressure greater than $140 / 90 \mathrm{mmHg}$ and $27 \%$ had abnormal albuminuria. In Hong Kong Chinese, diabetes mellitus is predominantly non-insulin-dependent even in the young. Obesity is more prevalent among females. Abnormal albuminuria is relatively common and is closely associated with hypertension and glycaemic control. In the light of increasing prevalence of diabetes among overseas Chinese, our findings may have important implications in the management of Chinese diabetic patients.

\section{Introduction}

Recent reports indicate that the prevalance of diabetes among Chinese living overseas is higher than those living in mainland China and is comparable to that in Caucasians. ${ }^{1-3}$ The proportion of non-insulin-dependent diabetes mellitus (NIDDM) compared to insulin-dependent diabetes mellitus (IDDM) is known to be higher among certain ethnic groups such as Indians, ${ }^{4,5}$ black Americans ${ }^{6}$ and Mexican Americans ${ }^{7}$ than among Caucasians. Complications such as proteinuria and hypertension are also more prevalent among these populations. $^{6-9}$

Correspondence: Juliana C.N. Chan, M.R.C.P.

*Present address: Department of Clinical Chemistry, 5/F, Guy's Tower, Guy's Hospital, St Thomas Street, London SE1 9RT, UK.

†Present address: Department of Medicine, The Christchurch School of Medicine, Christchurch Hospital, Christchurch, New Zealand.

Accepted: 30 September 1992
Microalbuminuria is considered to be a marker of incipient diabetic nephropathy in patients with IDDM and is closely associated with hypertension. ${ }^{10}$ In NIDDM, microalbuminuria is associated with increased risk for cardiovascular disease $\mathrm{s}^{11,12}$ but its role in predicting the onset of diabetic nephropathy remains to be established. ${ }^{13-15}$ Coexisting essential hypertension may partly explain the high prevalence of hypertension among patients with NIDDM..$^{16}$ Among Pima Indians who have high prevalance of NIDDM, proteinuria is associated with excess morbidity and mortality attributable to renal failure and cerebrovascular accident. ${ }^{17}$ These complications are known to be the principal causes of death in Chinese diabetic patients. ${ }^{18} \mathrm{~A}$ recent report indicates that there is a close link between hypertension and diabetes among Chinese living in Taiwan. ${ }^{19}$ We have previously reported high prevalence rates of abnormal albuminuria and transferrinuria among a separate and smaller group of Chinese patients with NIDDM. ${ }^{20,21}$ In the 
present study we have examined the pattern of diabetes with particular emphasis on the prevalence of obesity, hypertension and abnormal albuminuria and their inter-relationships among Hong Kong Chinese patients with NIDDM.

\section{Subjects and methods}

A total of 493 consecutive Chinese patients attending the diabetes clinic at the Prince of Wales Hospital, Shatin, Hong Kong were recruited during a 4 week period. All were restudied $8-16$ weeks later.

Patients were classified as insulin-dependent if they had started insulin therapy within 1 month of diagnosis and remained on it constantly since. Those not fulfilling these criteria were classified as non-insulin-dependent. Body weight (kg) and body height (m) were recorded at each visit. Obesity was defined as a mean body mass index (BMI) greater than $27 \mathrm{~kg} / \mathrm{m}^{2}$ for males or greater than $25 \mathrm{~kg} / \mathrm{m}^{2}$ for females. ${ }^{22}$ Blood pressure was measured (diastolic phase V) by a single trained research nurse using a standard mercury sphygmomanometer between 2 and 4 p.m. after the patient had remained seated for at least 5 minutes. Blood pressure was taken for familiarization purposes at the first visit and was recorded for analysis at the second visit. Arterial hypertension was diagnosed if the systolic blood pressure was greater than $160 \mathrm{mmHg}$ and/or diastolic blood pressure greater than $95 \mathrm{mmHg}$ or if the patient was on antihypertensive treatment. Systolic hypertension was considered to be present if the systolic blood pressure was greater than $160 \mathrm{mmHg} .^{23}$

Blood was drawn for measurements of glycosylated haemoglobin $\left(\mathrm{HbA}_{1}\right)$, random plasma glucose and creatinine concentrations. Urine creatinine concentration was measured by the Jaffe method on a Beckman Astra-8 Chemistry Analyser (Beckman Instrument Inc., Palo Alto, CA, USA). $\mathrm{HbA}_{1}$ was measured by gel electrophoresis (Ciba Corning Diagnostics Corp, Palo Alto, CA, USA) with a normal reference range of $6.5-8.5 \%$ and plasma glucose concentration, by a glucose oxidase method (Diagnostic Chemicals Ltd reagent kit).

A random untimed urine sample was collected between $11 \mathrm{a} . \mathrm{m}$. and $2 \mathrm{p} . \mathrm{m}$. for measurements of albumin and creatinine concentration and a midstream specimen of urine was obtained for culture to exclude urinary tract infection. These were repeated 8-16 weeks later. Urinary tract infection, if present, was treated and the urine collection then repeated. In order to validate the urine albumin/ creatinine $(\mathrm{UA} / \mathrm{Cr})$ ratio estimated in random urine specimens, every fifth patient was asked to collect, in addition, a 24 hour urine specimen.

All urine samples were stored at $4^{\circ} \mathrm{C}$ and analysed within 1 week of collection. Urine albumin concentration was measured by immunoturbidimetry modified from previously published methodology. ${ }^{24}$ Intra-assay and inter-assay coefficients of variation were $3.3 \%$ and $6.7 \%$, respectively, at concentrations of $2.5-80 \mathrm{mg} / \mathrm{l}$. The detection limit was $2.5 \mathrm{mg} / 1$.

Normoalbuminuria was considered to be present if the $\mathrm{UA} / \mathrm{Cr}$ ratio was consistently less than $5.4 \mathrm{mg} / \mathrm{mmol}$ (equivalent to a 24 hour urinary albumin excretion (UAE) of $30 \mathrm{mg} /$ day) in sterile samples on both occasions (see results). Patients were recalled for a third urine collection if the results of the initial two were inconsistent. Microalbuminuria was defined as a mean $\mathrm{UA} / \mathrm{Cr}$ ratio (dependent on either two or three visits) between 5.4 and $40.3 \mathrm{mg} / \mathrm{mmol}$ (equivalent to a 24 hour UAE of $30-300 \mathrm{mg} /$ day) and macroalbuminuria, as a mean $\mathrm{UA} / \mathrm{Cr}$ ratio greater than $40.3 \mathrm{mg} / \mathrm{mmol}$ (see results).

A total of 110 healthy Chinese volunteers were recruited from attendants of a day centre and hospital staff. There were 66 females (mean age: $60 \pm 17$ years; mean BMI of $25.8 \pm 4.4 \mathrm{~kg} / \mathrm{m}^{2}$ ) and 44 males (mean age: $48 \pm 13$ years; mean BMI: $23.7 \pm 2.8$ ). None of these subjects were taking medication. Hypertension and diabetes mellitus were excluded by blood pressure measurement (blood pressure less than $140 / 90 \mathrm{mmHg}$ ) and urinalysis for glucose. Urinary albumin excretion was measured using untimed random sterile urine samples obtained on two occasions. The UA/Cr ratio in the healthy controls was $0.02-2.99 \mathrm{mg} /$ mmol.

\section{Statistical analysis}

Statistical analysis was carried out using the ABstat Statistical Package (Anderson-Bell Corp. 1989) on an IBM computer. The mean values for all laboratory data obtained from the outpatient visits and the blood pressure reading from the second visit were used for statistical analysis. The urine results were positively skewed and were log transformed before analysis. All data were presented as mean \pm s.d. and median (range), as appropriate. Comparisons between patient groups were made with the Student's $t$-test, chi-square test and Mann-Whitney $U$-test, as appropriate. Relationships between the logarithm of $\mathrm{UA} / \mathrm{Cr}$ ratio and other variables were analysed by stepwise multiple regression analysis. A $P$ value less than 0.05 (two-tailed) was considered to be statistically significant. When multiple group comparisons were made, the $\boldsymbol{P}$ value was adjusted using Bonferroni's Inequality Theorem. 


\section{Results}

In 493 patients, 15 patients $(3.6 \%)$ were categorized as having IDDM and were excluded from the analysis. Twenty patients were excluded because of current or past disorders which may interfere with urine protein results (nine with a history of renal calculi, nine with malignancy and two with microscopic haematuria due to coincident glomerulonephritis). A further 61 patients were excluded because a second or third urine specimen could not be obtained. Complete data are presented for 397 patients classified as NIDDM.

\section{Clinical characteristics}

Table I gives the clinical details and laboratory data of the 397 patients included in the analysis. There was a female:male ratio of $3: 2$. Obesity was present in $17 \%$ of men (BMI $\left.>27 \mathrm{~kg} / \mathrm{m}^{2}\right)$ and $40 \%$ of females (BMI $\left.>25 \mathrm{~kg} / \mathrm{m}^{2}\right)$. Twenty-one per cent of patients gave a positive family history of diabetes involving at least one first degree relative. The insulin-treated $(25 \%)$ patients were younger ( $53 \pm 15$ vs $56 \pm 12$ years, $P<0.01$ ) and had longer duration of illness $(9.6 \pm 6.9 v s 5.1 \pm 4.9$ years, $P<0.001)$ compared to the non-insulin-treated (75\%) patients with NIDDM.

The age at diagnosis of diabetes was less than 35 years in 67 patients $(17 \%)$. Although $52 \%$ of these patients (35 of 67 patients) were insulin-treated, only $10 \%$ (seven of 67 patients) were classifiable as IDDM. Of the remaining 60 patients, obesity was present in $25 \%$ of males and $56 \%$ of females. Table II summarizes the clinical features and laboratory data of the obese and non-obese patients. At the time of the study, $7.8 \%$ of patients were aged less than $35(n=31)$. In this subgroup of patients, $29 \%$ of males and $65 \%$ of females were obese, five patients had microalbuminuria and one had blood pressure greater than $140 / 90 \mathrm{mmHg}$.

\section{Albuminuria and blood pressure}

Of the 397 patients, $193(48.6 \%)$ had hypertension, of whom $142(35.8 \%)$ were already receiving anti-hypertensive therapy when studied. Based on the reading obtained at the second visit, 11 patients $(2.8 \%)$ were diagnosed to have hypertension while 40 patients $(10.1 \%)$ were found to have systolic hypertension. An additional 27 patients $(6.8 \%)$ had borderline hypertension as defined by a blood pressure between 140/90 and/or $160 / 95 \mathrm{mmHg} .{ }^{23}$

In the patients in whom both were checked, there was a close correlation between the $\mathrm{UA} / \mathrm{Cr}$ ratio in the untimed sterile urine sample and the 24 hour UAE $(r=0.83, P<0.001)$. A $\mathrm{UA} / \mathrm{Cr}$ ratio of $5.4 \mathrm{mg} / \mathrm{mmol}$ corresponded to an UAE of $30 \mathrm{mg} /$ day and a UA/Cr ratio of $40.3 \mathrm{mg} / \mathrm{mmol}, 300 \mathrm{mg} /$ day (linear regression equation: $\log \mathrm{UA} / \mathrm{Cr}=$ $0.874755 \times \log$ UAE-0.407153). These values were therefore selected as cut-off points for data analysis (see Methods). Abnormal albuminuria was present in $47 \%$ of patients $-27 \%$ with microalbuminuria and $20 \%$ with macroalbuminuria. Plasma crea-尺 tinine concentration was greater than $120 \mu \mathrm{mol} / \mathrm{l}$ in 52 patients $(13 \%)$.

Among the treated hypertensive patients, the duration of hypertension was $4(0.5-20)$ years. There was no correlation between $\mathrm{UA} / \mathrm{Cr}$ ratio and duration of hypertension. We further studied the relationships between proteinuria and blood pressure, renal function, glycaemic control, age and duration of diabetes using stepwise multiple regres-

Table I Clinical features and laboratory data of the study population with non-insulin-dependent diabetes (NIDDM) $(n=397)$

\begin{tabular}{|c|c|c|}
\hline & $\begin{array}{c}\text { Male } \\
(\mathrm{n}=155)\end{array}$ & $\begin{array}{c}\text { Female } \\
(\mathrm{n}=242)\end{array}$ \\
\hline \multicolumn{3}{|l|}{ Clinical findings } \\
\hline Age (years)* & $57(17-80)$ & $57(22-89)$ \\
\hline Duration of diabetes (years)* & $4(0.5-30)$ & $4(0.5-30)$ \\
\hline Body mass index $\left(\mathrm{kg} / \mathrm{m}^{2}\right)$ & $24.2 \pm 3.6$ & $24.4 \pm 3.4$ \\
\hline Systolic blood pressure $(\mathrm{mmHg})$ & $142 \pm 29$ & $146 \pm 28$ \\
\hline Diastolic blood pressure (mmHg) & $80 \pm 13$ & $78 \pm 12$ \\
\hline Blood pressure $>140 / 90 \mathrm{mmHg}(\%)$ & 51 & 58 \\
\hline Abnormal albuminuria $(\%)$ & 41 & 49 \\
\hline \multicolumn{3}{|l|}{ Laboratory data } \\
\hline $\mathrm{HbA}_{1}(\%)$ & $10.6 \pm 2.3$ & $10.9 \pm 2.3$ \\
\hline Random plasma glucose concentration $(\mathrm{mmol} / \mathrm{l})$ & $10.3 \pm 5.4$ & $11.3 \pm 4.8$ \\
\hline Urine albumin/creatinine ratio $(\mathrm{mg} / \mathrm{mmol})^{*}$ & $3.0(0.4-475.0)$ & $4.3(0.4-924.5)$ \\
\hline Plasma creatinine concentration $(\mu \mathrm{mol} / \mathrm{l})^{*}$ & $92(58-1,085)$ & $71(49-569)$ \\
\hline
\end{tabular}

Mean \pm s.d.; ${ }^{*}$ median (range). 
Table II Clinical features and laboratory data of patients with NIDDM diagnosed before the age of 35

\begin{tabular}{lll}
\hline & \multicolumn{1}{c}{$\begin{array}{c}\text { Obese } \\
(\mathrm{n}=26)\end{array}$} & $\begin{array}{c}\text { Non-obese } \\
(\mathrm{n}=34)\end{array}$ \\
\hline $\begin{array}{l}\text { Clinical findings } \\
\text { Male (\%) }\end{array}$ & 25 & 75 \\
Age (years)* & $33(24-46)$ & $36(17-60)$ \\
Family history (\%) & 42 & 32 \\
Duration of diabetes (years)* & $3.5(0.5-20)$ & $8(0.5-30)$ \\
Insulin treated (\%) & 23 & 65 \\
Systolic blood pressure (mmHg) & $120 \pm 20$ & $129 \pm 25$ \\
Diastolic blood pressure (mmHg) & $73 \pm 13$ & $77 \pm 11$ \\
Blood pressure > 140/90 mmHg (\%) & 15 & 21 \\
Abnormal albuminuria (\%) & 31 & 24 \\
Laboratory data & & $11.2 \pm 3.3$ \\
HbA $(\%)$ & $10.7 \pm 2.1$ & $11.7 \pm 8.5$ \\
Random plasma glucose concentration $(\mathrm{mmol} / \mathrm{l})$ & $9.7 \pm 4.0$ & $1.9(0.6-475)$ \\
Urine albumin/creatinine ratio $(\mathrm{mg} / \mathrm{mmol}) *$ & $82(53-267)$ \\
Plasma creatinine concentration $(\mu \mathrm{mol} / \mathrm{l})^{*}$ & $67(0.8-155.8)$ & \\
\hline
\end{tabular}

Mean \pm s.d.; *median (range).

Note: Obesity defined as BMI $>27 \mathrm{~kg} / \mathrm{m}^{2}$ in males and $>25 \mathrm{~kg} / \mathrm{m}^{2}$ in females.

sion analysis. In the whole group $\left(R^{2}=0.34\right.$, $F=65.42, P<0.001$ ), there were significant associations between $\mathrm{UA} / \mathrm{Cr}$ ratio and systolic blood pressure $(\beta=0.40, P<0.001)$, plasma creatinine concentration $(\beta=0.27, P<0.001)$ and $\mathrm{HbA}_{1}$ $(\beta=0.20, P<0.001)$. Figure 1 shows the UA/Cr ratio between the normotensive and hypertensive patients. Patients with treated hypertension and systolic hypertension had significantly higher UA/ Cr ratio compared to patients with normotension and borderline hypertension. There was no difference in the $\mathrm{UA} / \mathrm{Cr}$ ratio between the treated hypertensive patients and those who were newly diagnosed during the present study.

Table III compares the clinical characteristics and laboratory data of NIDDM patients with normo-, micro- and macroalbuminuria. Those with abnormal albuminuria were older, had higher blood pressures, plasma creatinine concentrations and $\mathbf{H b A}_{1}$. While increasing severity of albuminuria was associated with increasing prevalance of hypertension, $40 \%$ of patients with normoalbuminuria also has hypertension. A total of $40 \%(99$ of 249) of patients with duration of disease less than 5 years and $49 \%$ (38 of 78 patients) who had a history of diabetes for between 5 and 10 years had abnormal albuminuria. Only the macroalbuminuric patients had significantly longer duration of diabetes compared to the normoalbuminuric patients.

Among patients with NIDDM diagnosed before the age of $35,18 \%$ had blood pressure greater than $140 / 90 \mathrm{mmHg}$ and $27 \%$ had abnormal albuminuria $(19 \%$ with microalbuminuria and $8 \%$ with macroalbuminuria). Table II further compares the clinical characteristics and laboratory data between the obese and non-obese patients in this subgroup.

\section{Discussion}

Our study re-emphasizes the low proportion of IDDM in Orientals even among young patients. ${ }^{25}$ Given that IDDM patients are more likely to attend a diabetic clinic, the relative prevalance of IDDM compared to NIDDM in Hong Kong Chinese may therefore be even lower. In a recent study, obesity and family history were found to be important risk factors for the development of NIDDM among Chinese. It has also been shown that females over the age of 50 have a higher prevalence of diabetes compared with males. ${ }^{1}$ In this regard, it is noteworthy that the mean age of the study population was over 50 years and that obesity was more prevalent among the females (control and patients). This may partially explain the finding of female preponderance of diabetes in the present study. Furthermore, family history is common and is particularly prevalent among patients diagnosed before the age of 35 . Some of these patients have features suggestive of maturity onset diabetes of the young, ${ }^{26}$ while other patients exhibit features similar to that of 'NIDDM of young onset' described among Caucasians. ${ }^{27}$ These patients are non-obese and not ketosis prone but remain vulnerable to microangiopathic complications. ${ }^{28}$ Although the non-obese patients tend to have longer duration of disease and frequently require insulin for control, prevalence rates of 


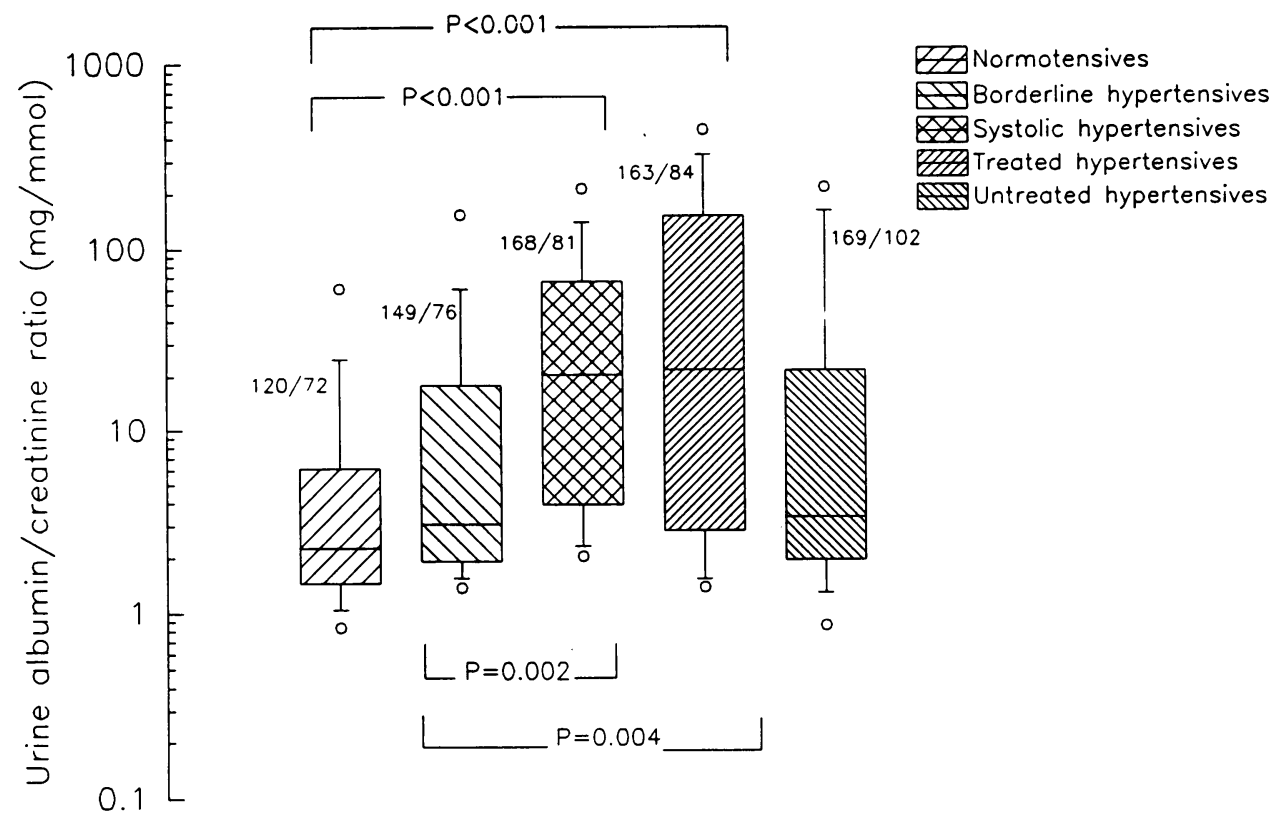

Figure 1 A boxplot showing the distribution of $\mathrm{UA} / \mathrm{Cr}$ ratio $(\mathrm{mg} / \mathrm{mmol})$ expressed on a logarithmic scale in normotensive and hypertensive patients with non-insulin-dependent diabetes (NIDDM). The 25th and 75th percentiles are represented by the lower and upper margins of the rectangle, respectively, and the median is shown within the rectangle. The extended arms represent the 10 th and 90 th percentiles with data points outside these limits summarized at the 5th and 95th percentiles. The mean blood pressure $(\mathrm{mmHg})$ for each group is also shown. An adjusted $P$ value $<0.005$ was taken to be statistically significant for multiple group comparisons.

Table III Comparison between non-insulin-dependent diabetic patients with normoalbuminuria, microalbuminuria and macroalbuminuria

\begin{tabular}{lccc}
\hline & $\begin{array}{c}\text { Normoalbuminuria } \\
(\mathrm{n}=214)\end{array}$ & $\begin{array}{c}\text { Microalbuminuria } \\
(\mathrm{n}=107)\end{array}$ & $\begin{array}{c}\text { Macroalbuminuria } \\
(\mathrm{n}=76)\end{array}$ \\
\hline Prevalence (\%) & 54 & 27 & 20 \\
Mean age (years)* & $53(17-84)$ & $59(27-89) \ddagger$ & $60(37-80) \S$ \\
Mean duration of diabetes (years)* & $4(0.5-30)$ & $4.5(0.5-22)$ & $8(1-30) \S \uparrow$ \\
Systolic blood pressure (mmHg) & $133 \pm 24$ & $152 \pm 28 \ddagger$ & $165 \pm 25 \S \|$ \\
Diastolic blood pressure (mmHg) & $76 \pm 11$ & $82 \pm 11 \ddagger$ & $83 \pm 13 \S$ \\
Hypertensives (\%) & 40 & $64 \|$ & $88 \S \|$ \\
Plasma creatinine concentration $(\mu \mathrm{mol} / \mathrm{l}) *$ & $76(53-164)$ & $81(49-343) \dagger$ & $120(51-1,085) \S \|$ \\
HbA $_{1}(\%)$ & $10.4 \pm 2.0$ & $11.2 \pm 2.3 \dagger$ & $11.4 \pm 2.7 \S$ \\
\hline
\end{tabular}

Mean \pm s.d.; *median (range); normoalbuminuria $v s$ microalbuminuria, $\dagger P<0.01, \ddagger P<0.001$; normoalbuminuria $v s$ macroalbuminuria, $\S P<0.001$; microalbuminuria $v s$ macroalbuminuria, $\uparrow P<0.01, \| P<0.001 ; P<0.016$ considered as significant for multiple group comparisons.

abnormal albuminuria are similar in both groups of patients and are present in up to $30 \%$ of patients despite a duration of disease less than 10 years. The insidious onset of symptoms may explain the late presentation of many of these patients in whom complications are often detectable at or shortly after diagnosis.
In order to study a large number of patients, we used random spot urine samples for documentation of proteinuria rather than timed collections. Our findings accord with a recent suggestion that a random daytime urine sample can provide a good index of daily urine albumin excretion. ${ }^{29}$ Albuminuria was measured on at least two occasions to 
reduce the possibility of misclassification arising from intra-individual variation. ${ }^{30}$ Despite a normal range of less than $3 \mathrm{mg} / \mathrm{mmol}$, our use of a higher cut-off value of $5.4 \mathrm{mg} / \mathrm{mmol}$ suggests that, if anything, we may have underestimated the prevalence of abnormal albuminuria.

The prevalence of abnormal albuminuria in this study is comparable to that in Pima Indians who also have a high prevalence of NIDDM ${ }^{31}$ and parallels the situation in Caucasians with IDDM. ${ }^{32}$ Caucasian patients with NIDDM have also been reported to have higher prevalence rates of abnormal albuminuria compared to patients with IDDM.$^{33}$ In our study, significant albuminuria was detectable in many patients despite diagnosis of diabetes less than 5 years previously. While these findings may reflect late diagnosis, factors other than duration of disease may also play a causal role in the development of abnormal albuminuria, such as high blood pressure.

In IDDM, persistent albuminuria has been reported to precede the increase of arterial blood pressure $^{34}$ and the prevalence of hypertension correlates with the duration of diabetes and the progression of nephropathy. ${ }^{10}$ In NIDDM, the association of coexisting essential hypertension may partly explain the high prevalence of hypertension. ${ }^{16}$ Despite the inherent limitations of a single blood pressure measurement and the possibility of overestimation of hypertension prevalence in our study population, our findings that nearly $40 \%$ of normoalbuminuric patients have hypertension accord with a recent report of a $34 \%$ prevalence rate of coexisting hypertension among diabetic Chinese in Taiwan. ${ }^{13}$ Furthermore, there is a consistent tendency for increasing severity of albuminuria to be associated with increasing prevalence of hypertension among our patients. Taking in conjunction with the less obvious relationship between duration of disease and proteinuria, our findings suggest that proteinuria among Chinese patients with NIDDM may have different aetiological connotations compared to other microangiopathic complications in Caucasians with IDDM with hypertension playing a particularly important role. Apart from the high prevalence of hypertension, glycaemic control is also found to be closely associated with proteinuria so that the high prevalence of abnormal albuminuria may be related to the overall poor glycaemic control of the study population. It has recently been reported that long-term improved glycaemic control had a beneficial impact on non-proliferative retinopathy, ${ }^{35}$ although effects on proteinuria are less clear.

Effective anti-hypertensive treatment has been shown to reduce proteinuria and slow deterioration of renal function in patients with IDDM. ${ }^{36}$ In our study while there were significant differences in the
$\mathrm{UA} / \mathrm{Cr}$ ratio between normotensive and hypertensive patients, no difference was observed between the newly diagnosed untreated hypertensive patients and those who were established on treatment. The severity of renal impairment in the latter may have rendered anti-hypertensive treatment less effective as suggested by the similar blood pressure readings between these two groups. Alternatively, it is possible that without anti-hypertensive therapy, the treated patients would have had more severe proteinuria and renal impairment. Finally, it is possible that certain anti-hypertensive agents may fail to improve or even increase the proteinuria in Chinese diabetic patients. Relatively little is known regarding the effects of anti-hypertensive treatment and the efficacy of different classes of anti-hypertensive drugs on proteinuria in NIDDM. ${ }^{10}$

Our study shows that the prevalence of abnormal albuminuria among the Hong Kong Chinese with NIDDM is similar to Caucasians with IDDM and higher than that reported in a comparable Caucasian population with NIDDM attending hospital outpatient clinics. ${ }^{33}$ The high prevalence of hypertension further increases the risk of development of renal disease and accords with earlier observations that renal failure and cerebrovascular disease are the leading causes of death among Hong Kong Chinese patients with diabetes. ${ }^{18}$

In conclusion, diabetes mellitus among the Hong Kong Chinese is predominantly non-insulindependent even among the young. Obesity is more prevalent among the females. There are high prevalence rates of hypertension, abnormal albuminuria and renal impairment. The prevalence and severity of abnormal albuminuria are increased in the presence of both hypertension and poor glycaemic control. The coexistence of hypertension in the presence of normoalbuminuria and the less well-defined relationship between duration of disease and proteinuria suggest that the nature of association between hypertension, diabetes and proteinuria among our study population is different from that in Caucasians with IDDM. Our findings may have important implications in the management of Chinese diabetic patients especially in the light of the rising trend of the disease among non-Caucasian populations.

\section{Acknowledgements}

We are indebted to Mr Joseph Lau from the Centre for Clinical Trials and Epidemiological Research, Chinese University of Hong Kong, for his advice on the analysis of the data. We thank our research nurse, Ms Margaret Cheung for her dedication. The study was part of our continuing research project supported by the Croucher Foundation Research Grant on the epidemiology and pathophysiology of diabetes mellitus and its complications in the Hong Kong Chinese. 


\section{References}

1. Chou, P., Chen, H.H. \& Hsiao, K.J. Community-based epidemiological study on diabetes in Pu-Li, Taiwan. Diabetes Care 1991, 15: 81-89.

2. Woo, J., Swaminathan, R., Cockram, C.S. et al. The prevalence of diabetes mellitus and an assessment of methods for detection among a community of elderly Chinese in Hong Kong. Diabetologia 1987, 30: 863-868.

3. World Health Organisation Ad Hoc Diabetes Reporting Group. Global estimates for the prevalence rates of diabetes mellitus and impaired glucose tolerance in adults. Diabetes Care 1993, 16: 157-177.

4. Mather, H.M. \& Keen, H. The Southall diabetes survey: prevalence of known diabetes in Asians against Europeans. Br Med J 1985, 291: 1081-1084.

5. Simmons, D., Williams, D.R.R. \& Powell, M.J. Prevalence of diabetes in a predominantly Asian community: preliminary findings of the Coventry diabetes study. $\mathrm{Br}$ Med J 1989, 298: 18-21.

6. Tierney, M.W., McDonald, C.J. \& Luft, F.C. Renal disease in hypertensive adults: effect of race and type II diabetes mellitus. Am J Kidney Dis 1989, 13: 485-493.

7. Haffner, S.M., Mitchell, B.D., Pugh, J.A. et al. Proteinuria in Mexican Americans and non-Hispanic Whites with NIDDM. Diabetes Care 1989, 12: 530-536.

8. Cowie, C.C., Port, F.K. \& Wolfe, R.A. Disparities in incidence of diabetes end stage renal disease according to race and type of diabetes. $N$ Engl J Med 1989, 321: 1074-1079.

9. Allawi, J., Rao, P.V., Gilbert, R. et al. Microalbuminuria in non-insulin-dependent diabetes: its prevalence in Indian compared with Europoid patients. $\mathrm{Br} \mathrm{Med} J$ 1988, 296: 462-464.

10. Selby, J.V., FitzSimmons, S.C., Newman, J.M., Katz, P.P., Sepe, S. \& Showstack, J. The natural history of epidemiology of diabetic nephropathy. Implication for prevention and control. JAMA 1990, 263: 1945-1960.

11. Jarrett, R.J., Viberti, G.C., Argyropoulos, A., Hill, R.D., Mahmud, U. \& Murrells, T.J. Microalbuminuria predicts mortality in non-insulin-dependent diabetes. Diabetic Med 1984, 1: 17-19.

12. Mattock, M.B., Keen, H., Viberti, G.C. et al. Coronary heart disease and urinary albumin excretion rate in Type 2 (non-insulin-dependent) diabetic patients. Diabetologia 1988, 31: 82-87.

13. Mogensen, C.E. Microalbuminuria predicts clinical proteinuria and early mortality in maturity-onset diabetes. $N$ Engl J Med 1984, 310: 356-360.

14. Martin, P., Hampton, K.K., Walton, C., Tindall, H. \& Davies, J.A. Microalbuminuria in type 2 diabetes mellitus from diagnosis. Diabetic Med 1990, 7: 315-318.

15. Schmitz, A., Gundersen, H.J.G. \& Osterby, R. Glomerular morphology by light microscopy in non-insulin-dependent diabetes mellitus. Lack of glomerular hypertrophy. Diabetes 1988, 37: 38-43.

16. Ferrannini, E. \& DeFronzo, R.A. The association of hypertension, diabetes and obesity: a review. J Nephrol 1989, 1: 3-15.

17. Nelson, R.G., Pettitt, D.J., Carraher, M.J., Baird, H.R. \& Knowler, W.C. Effect of proteinuria on mortality in NIDDM. Diabetes 1988, 37: 1499-1504.

18. Diabetes Drafting Group. Prevalence of small vessel and large vessel disease in diabetic patients from 14 centres. The World Health Organisation Multinational Study of Vascular Disease in Diabetics. Diabetologia 1985, 28: 615-640.

19. Tai, T.Y., Chuang, L.M., Chen, C.J. \& Lin, B.J. Link between hypertension and diabetes mellitus epidemiological study of Chinese adults in Taiwan. Diabetes Care 1991, 14: 10131020.
20. Cheung, C.K., Yeung, V.T.F., Cockram, C.S. \& Swaminathan, R. Urinary excretion of albumin and enzymes in 2 non-insulin-dependent Chinese diabetics. Clin Nephrol 1990, 34: $125-130$.

21. Cheung, C.K., Cockram, C.S., Yeung, V.T.F. \& Swami- $\stackrel{\vec{\rho}}{\vec{D}}$ nathan, R. Urinary excretion of transferrin by non-insulindependent diabetics: a marker for early complications? Clin Chem 1989, 35: 1672-1674.

22. National Diabetes Data Group: Classification and diagnosis of diabetes mellitus and other categories of glucose in- $\unrhd$ tolerance. Diabetes 1979, 28: 1039-1057.

23. Arterial Hypertension. Report on a WHO Expert Committee, Technical Report Series 628 World Health Organisation, $\vec{\circ}$ Geneva, 1978.

24. Cheung, C.K. \& Swaminathan, R. Automated immunoturbidimetric method for the determination of retinol binding protein, prealbumin and transferrin in urine. Clin Biochem 1989, 22: 425-427.

25. Tajiman, N., La Porte, R.E., Hibi, I., Kitagawa, T., Fujita, H. \& Drash, A.L. A comparison of the epidemiology of youth-onset insulin-dependent diabetes mellitus between $\infty$ Japan and the United States (Allegheny Pennsylvania). Diabetes Care 1985, 8 (Suppl 1): 17-23.

26. Tattersall, R.B. Mild familial diabetes with dominant inheritance. $Q J$ Med 1974, 43: 339-357.

27. O'Rahilly, S., Spivey, R.S., Holman, R.R., Nugent, Z., Clark, 윽 A. \& Turner, R.C. Type II diabetes of early onset: a distinct clinical and genetic syndrome? Br Med J 1987, 294: 923-928. \

28. Chan, J.C.N., Hawkins, B.R. \& Cockram, C.S. A Chinese family with non-insulin-dependent diabetes of early onset. $\frac{\hat{S}}{\square}$ Diabetic Med 1990, 7: 211-214.

29. Rowe, D.J.F., Dawnay, A. \& Watts, G.F. Microalbuminur? $\overrightarrow{0}$ in diabetes mellitus: review and recommendations for the measurement of albumin in urine. Ann Clin Biochem 1990, 2 . 297-312.

30. Feldt-Rasmussen, B. \& Mathiesen, E.R. Variability of urinary albumin excretion in incipient diabetic nephropathy. Diabetic Nephrol 1984, 3: 101-103.

31. Nelson, R.G., Kunzelman, C.L., Pettitt, D.J., Saad, M.F., Bennett, P.H. \& Knowler, W.C. Albuminuria in NIDDM (non-insulin-dependent) diabetes mellitus and glucose tol- $\vec{F}$ erance in Pima Indians. Diabetologia 1989, 32: 870-876.

32. Parving, H.H., Hommel, E., Mathiesen, R. et al. Prevalence of microalbuminuria, arterial hypertension, retinopathy and neuropathy in patients with insulin dependent diabetes. $\mathrm{Br}$ Med J 1988, 296: 156-160.

33. Marshall, S.M. \& Alberti, K.G.M.M. Comparison of the prevalence and associated features of abnormal albumin excretion in insulin-dependent and non-insulin-dependent diabetes. $Q J$ Med 1989, 70: 61-71.

34. Mathiesen, E.R., Rønn, B., Jensen, T., Storm, B. \& Deckert, $T$. Relationship between blood pressure and urinary albumin excretion in development of microalbuminuria. Diabetes 1990, 39: 245-249.

35. Brinchmann-Hansen, O., Dahl-Jørgensen, D., Sandvik, L. \& Hanssen, K.F. Blood glucose concentrations and progression of diabetic retinopathy: the seven year results of the Oslo study. Br Med J 1992, 304: 19-22.

36. Parving, H.H., Anderson, A.R., Smidt, U.M. \& Svendsen, P.A. Early aggressive antihypertensive treatment reduces rate of decline in kidney function in diabetic nephropathy. Lancet 1983, i: 1175-1178. 